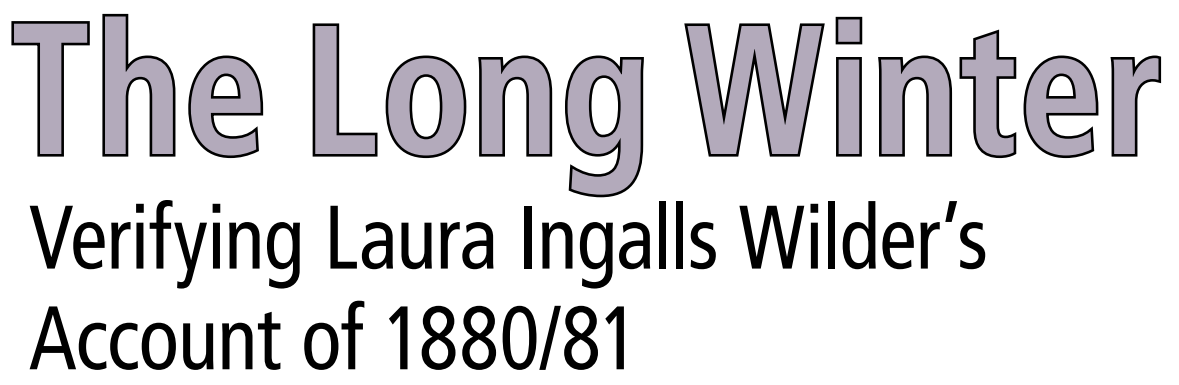

Adapted from "The Long Winter of 1880/81," by Barbara Mayes Boustead (University of NebraskaLincoln), Martha D. Shulski, and Steven D. Hilberg. Published online in BAMS, June 2020. For the full, citable article, see DOI:10.1175 /BAMS-D-19-0014.1.
There were houses in town, but not even a light from one of them could reach another. And the town was all alone on the frozen, endless prairie, where snow drifted and winds howled and the whirling blizzard put out the stars and the sun.

—Laura Ingalls Wilder, The Long Winter

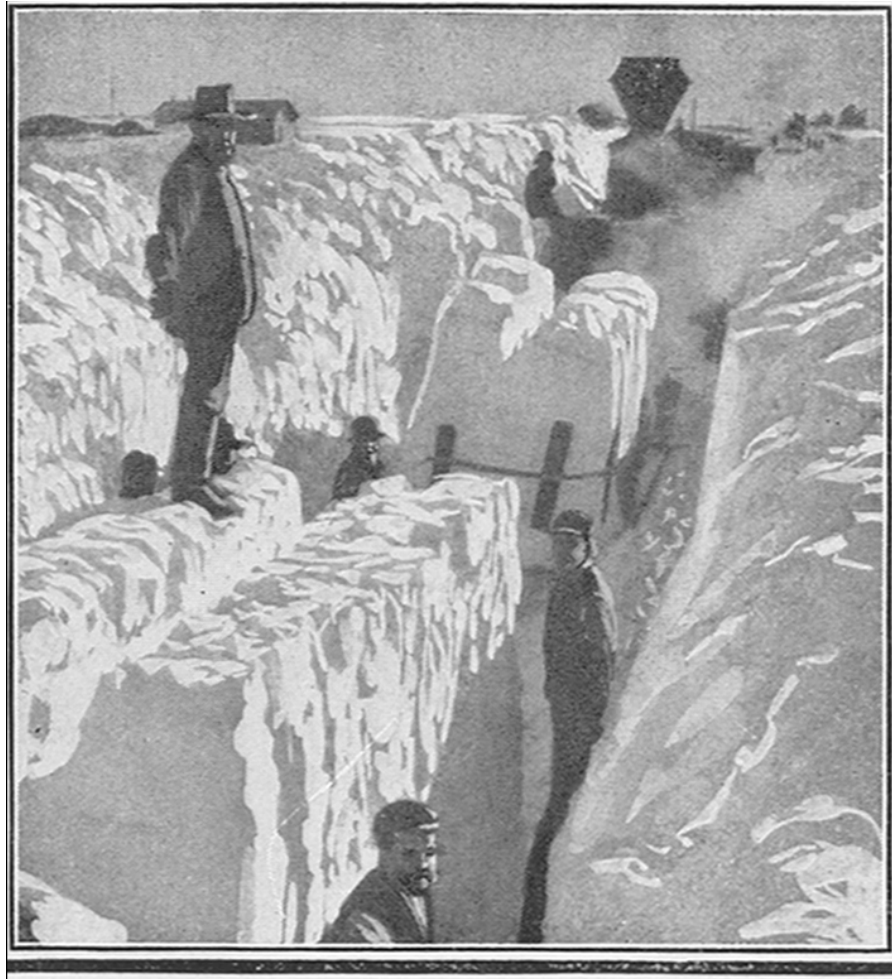

OPENING THE ROAD IN 1881.

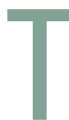

he winter of 1880/81 featured in the Laura Ingalls Wilder historical fiction book, The Long Winter, was strikingly difficult across much of the Plains and Midwest. One of a number of accounts of that harrowing winter, sometimes referred to as the "Hard Winter" or the "Starvation Winter," Wilder's story is set in De Smet, Dakota Territory (present-day South Dakota; 60 km west of Brookings). The Long Winter is fiction, but it contains many verifiable facts, including those regarding the weather of the Hard Winter.

Laura Ingalls Wilder (1867-1957) wrote the Little House book series between 1932 and 1943 to chronicle her childhood as her family migrated among Wisconsin, Kansas, Minnesota, Iowa, and 
eventually Dakota Territory (South Dakota). There, at age 18, Laura married Almanzo Wilder; their daughter, Rose, was born a year later. The books are laced with details of specific weather and climate events. In adulthood, Rose edited Laura's works, and as a result some aspects of the books are more fictionalized than others.

We set out to determine which parts of Laura's stories are based in fact, and in the process, filled in the gap left by the absence of analysis or documentation in scientific literature about the Hard Winter of $1880 / 81$. Examining the Hard Winter allows us to place recent severe winters, such as 2013/14, into context.

\section{Meteorological data}

Meteorological datasets in the central Plains region that predate the Hard Winter and continue through the present are sparse. The few available official and routine observations must be supplemented with historical and anecdotal information to meaningfully describe the winter of $1880 / 81$. Station-based data are

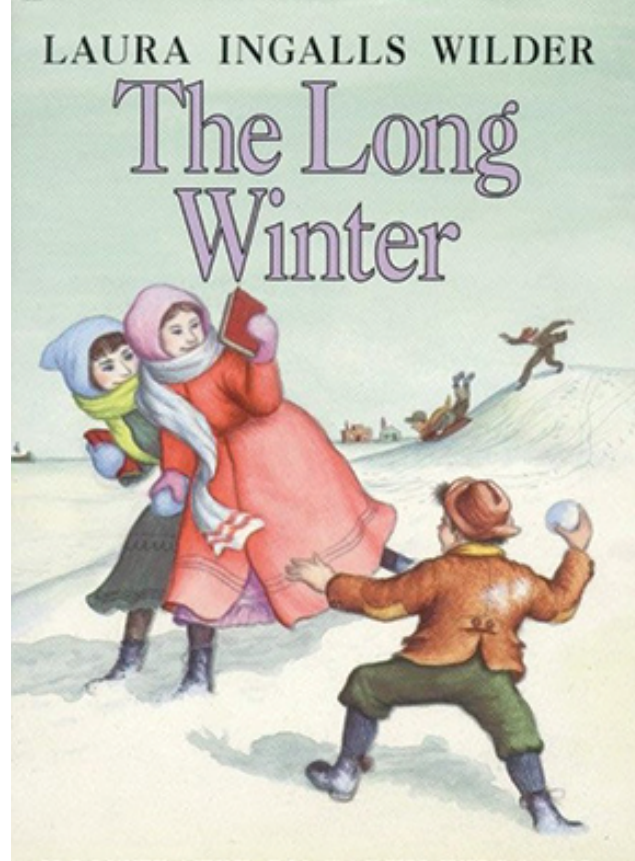

ILLUSTRATED BY GARTH WILLIAMS

* Locations with data available for the winter of $1880 / 81$. Sites marked with a flag are CDMP sites; others are sites with continuous records. De Smet, South Dakota-the setting of Laura Ingalls Wilder's The Long Winteralso is noted for reference. Huron, South Dakota, was not available until April 1881 and also is included for reference. available from the Applied Climate Information System, and additionally, the Climate Database Modernization Project (CDMP) has digitized historical observations previously unavailable for computer analyses and in closer proximity to De Smet. The historical observations often include temperature, precipitation, and wind, as well as information about other meteorological and astronomical phenomena.

Snowfall or snow depth measurements during the winter of 1880/81 were not available, but we derived occurrences of snow from temperature and precipitation data. The Accumulated Winter Season Severity Index (AWSSI) assigns values to each day of a winter season based on thresholds of maximum and minimum temperatures, as well as derived snowfall and snow depth; the sum of daily values through a winter characterizes the severity of that season. AWSSI can also assess temperature and snow separately to contextualize their relative contributions to the winter severity. The precipitation-based pAWSSI provides a longer period of record for locations that do not have direct snowfall and snow depth measurements. This allows analysis of the winter of 1880/81 based on existing records. Some sites do have records predating the winter of 1880/81 and allow for direct comparison to more recent ones; other sites with records for one or a few winters can place nearby stations into context.

Additionally, using gridded reanalysis data based on synoptic pressure, sea surface temperature, and sea ice distribution, and available through the NOAA Earth Systems Research 


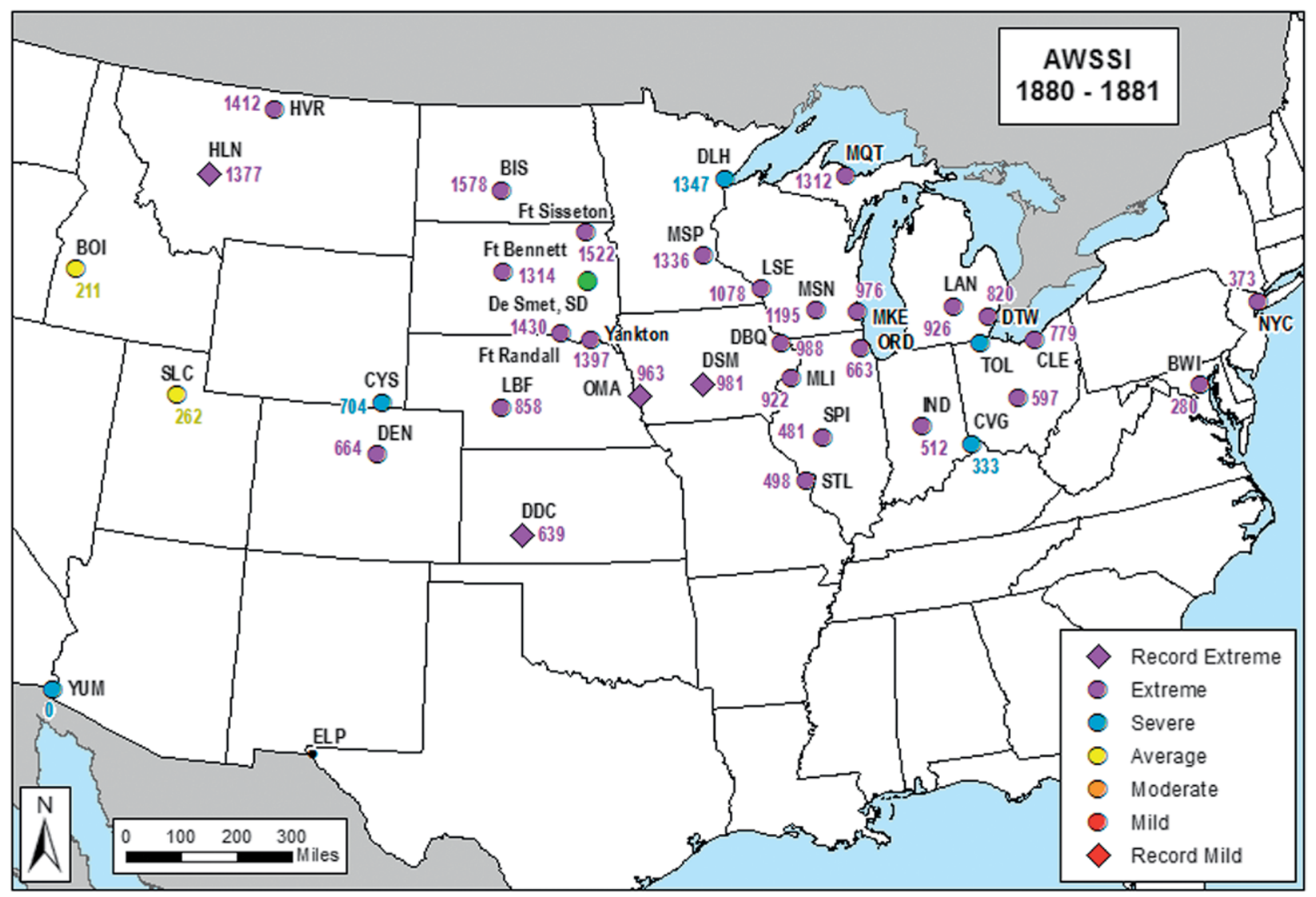

Laboratory, we constructed composites of synoptic fields relative to both a modern base period (1981-2010) and a late-1800s base period (1871-1900), depending on the application and field being investigated.

\section{Overview of the winter of $1880 / 81$}

\section{"A b-b-b-b-blizzard!" Ma chattered. "In Oc-October! I n-n-never heard of..." \\ -Laura Ingalls Wilder, The Long Winter}

The winter began early, with a blizzard in eastern South Dakota and surrounding areas on 15-18 October 1880. A surface low-pressure system stalled in northwest Iowa and northeast Nebraska, producing subfreezing temperatures, snow, and strong winds due to a tight surface pressure gradient. Snowfall and blowing snow lasted 2-3 days in the region, with Laura's account supported by observations from both continuous and CDMP station records.

Following a respite after the October blizzard, wintry conditions returned by mid-November, followed by a number of snow and potential
$\Delta$ culated value at observing sites, with category color-coded based on the period of record for each site. Record extreme sites are denoted with a purple diamond marker. De Smet, South Dakota, is included on the map (green dot) for reference. blizzard events in December. After a cold but relatively snow-free period, storm frequency increased from early January through February, producing snow almost daily among the CDMP sites in eastern South Dakota as well as nearby long-term stations.

In March, most days remained below freezing at all sites in the region, though snowfall frequency decreased. Cold conditions continued into the first half of April. The last suspected snow event occurred across the region on 10-12 April 1881. From 14 April onward, maximum temperatures rose above freezing each day and remained there throughout the spring.

While clearly a harsh winter, was it the most severe ever in the De Smet area? According to the pAWSSI, the Hard Winter did indeed rank as the most extreme in the period of record at Omaha, Nebraska; Des Moines, Iowa; Dodge City, Kansas; and Helena, Montana, as well as the second most extreme at Minneapolis-Saint Paul. All nearby CDMP sites had near-record pAWSSI values when compared to nearby long-term stations at Aberdeen, South Dakota; Fargo, North Dakota; Huron, South Dakota; 


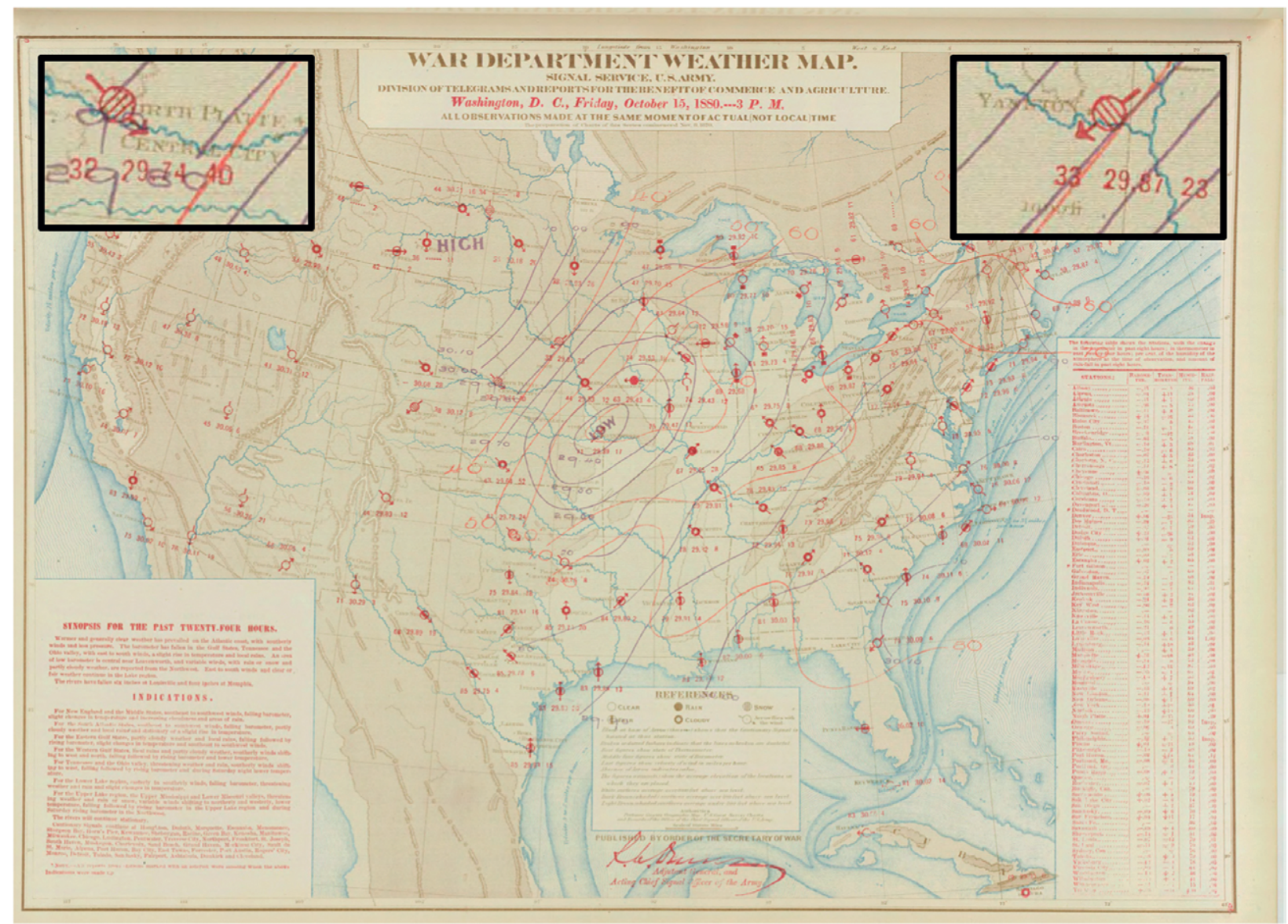

and Pierre, South Dakota. The temperature component of pAWSSI at continuous sites was the coldest on record at both Des Moines and Omaha, and 4th highest at Detroit (DTW) and Lansing (LAN), Michigan, but it was “only" in the coldest 20 at Minneapolis-Saint Paul. According to pAWSSI, Minneapolis-Saint Paul endured its highest snow ranking on record and Des Moines ranked as second highest; DTW and LAN were in the top 3 and 6, respectively. Among the CDMP sites, most of the pAWSSI accumulations for the snow component were well above normal but not near records.

In many locations, the more devastating impact of the Hard Winter was the rapid snowmelt and rain in spring. Much of the north-central United States had severe ice jam and snowmelt flooding. Major rivers swelled to record levels that stood for decades and, in a few locations, still stand, severely damaging many towns and prompting resettlement to higher ground or even spelling the end of some settlements.

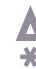
* Surface analysis at 2000 UTC (3 p.m. Eastern Standard Time) 15 Oct 1880. Yankton, South Dakota (upper right), and North Platte, Nebraska (upper left), stations are in insets. 

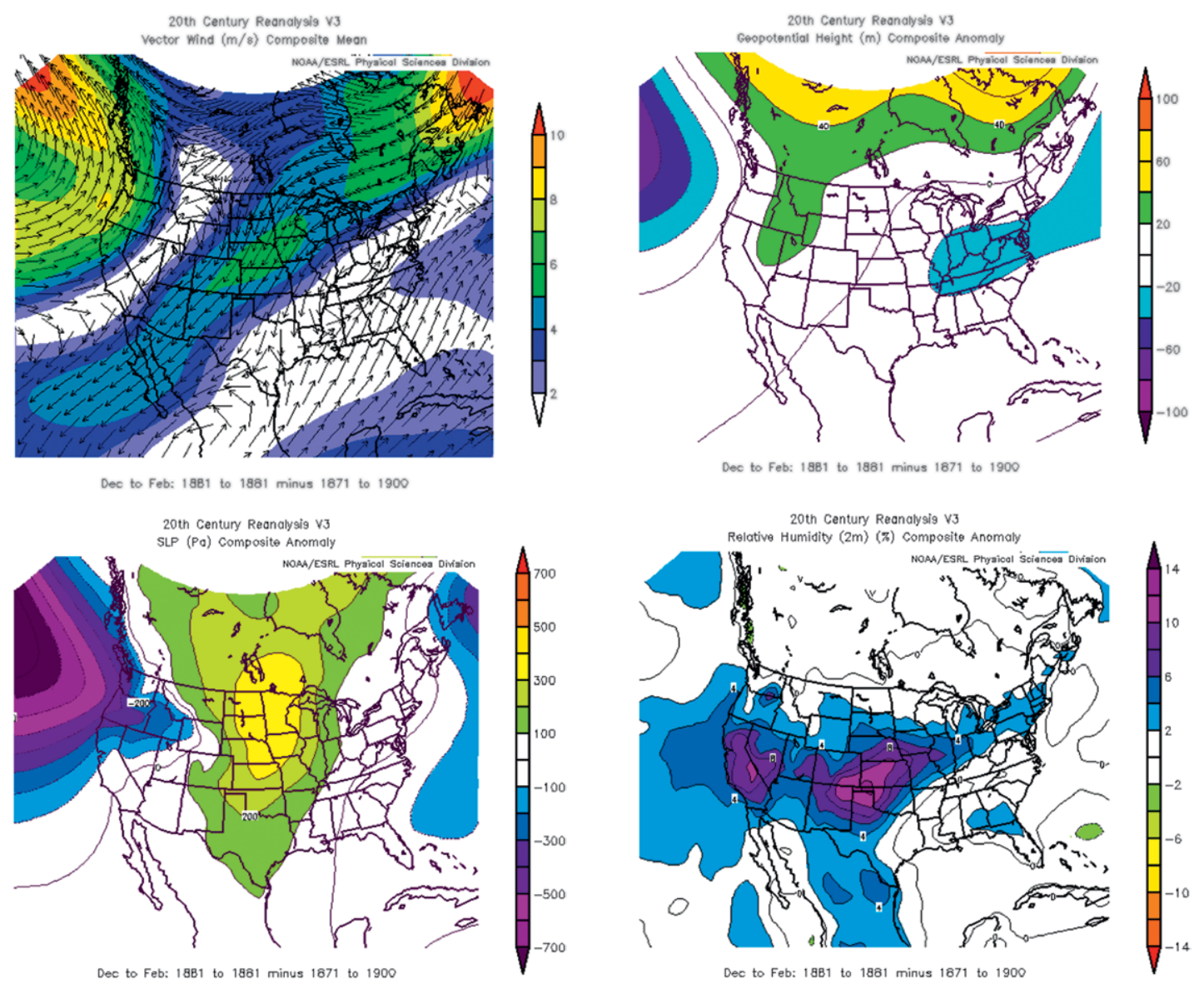

colder base climate state of 1871-1900, reflects the canonical negative-NAO pattern.

We obtained reconstructed monthly SST anomaly data to produce Oceanic Niño Index (ONI) calculations to designate El NiñoSouthern Oscillation (ENSO) phases. While the winter of 1880/81 lacked canonical El Niño features like an unusually strong subtropical jet across the southern United States or Gulf of Mexico, the data support the conclusion that a weak to moderate El Niño was in place.

While possibly less influential, other teleconnection patterns, as well as internal atmospheric variability, influenced the winter of 1880/81. The Pacific Decadal Oscillation (PDO), which is a combination of physical processes, was mostly negative to slightly positive from September 1880 through April 1881. The negative phase of PDO can be accompanied by negative temperature anomalies in the western Great Lakes to northern and central Plains and much of the Rockies.

In its negative phase, associated with gfd, the Tropical/Northern Hemisphere (TNH) pattern can be linked to negative temperature
* For DJF 1880/81, the anomalies relative to the 1871-1900 base period for $300-\mathrm{hPa}$ wind $\left(\mathrm{m} \mathrm{s}^{-1}\right)$, 500-hPa geopotential height $(\mathbf{m})$, sea-level pressure $(\mathrm{Pa})$, and 2-m relative humidity (\%). anomalies from the Great Lakes through the Plains and toward the Rockies, along with unusually wet conditions from Minnesota across the Dakotas and to the Rockies. The available data infers a negative TNH pattern for December 1880 through February 1881.

Another pattern associated with wintertime impacts in interior North America, the Pacific/North American (PNA) pattern, also tends to follow ENSO. A positive PNA pattern is typically associated with above-normal temperatures in the northwestern half of the continental United States, including the central and northern Plains to the Midwest and Great Lakes. The 500-hPa geopotential height and $300-\mathrm{hPa}$ wind patterns of December through February 1880/81 loosely and weakly reflect a positive PNA pattern.

The combination of discernible teleconnections adds weight to the conclusion that the winter of 1880/81 was the product of a deeply anomalous pattern. While these teleconnections set the stage for the Hard Winter, synoptic parameters explain the observed weather. For example, anomalous high pressure extended from 


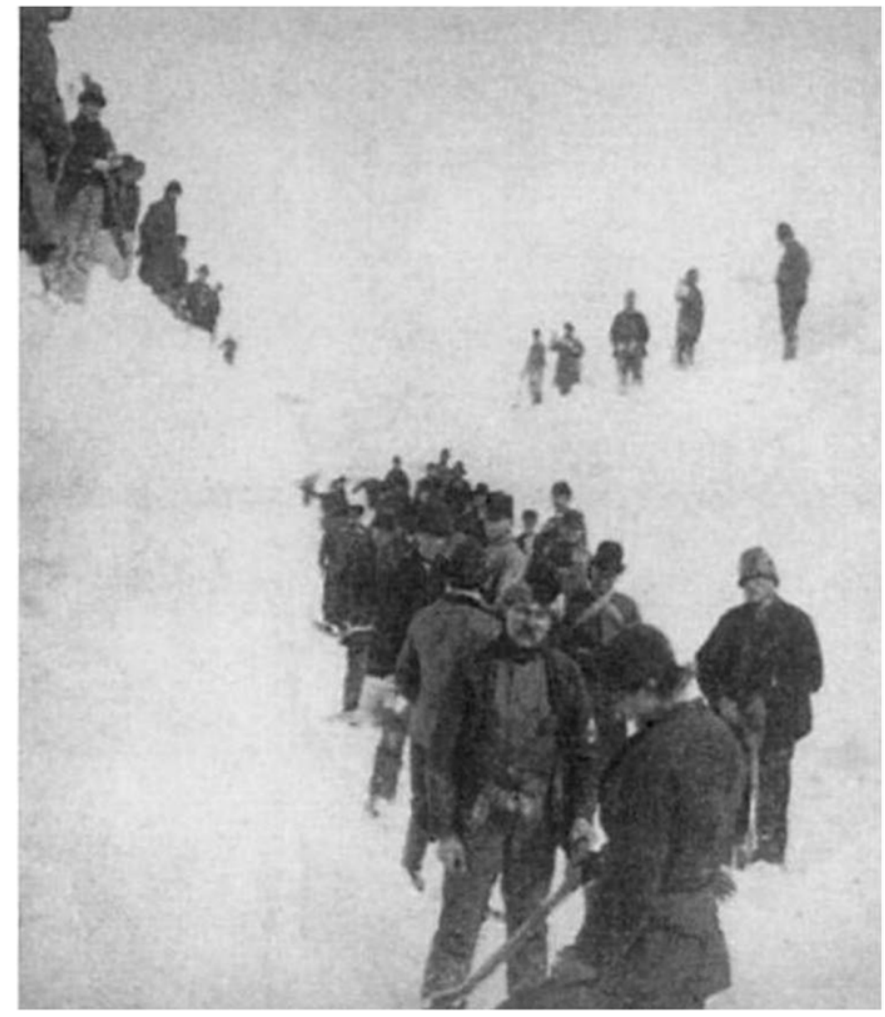

4 * Cleaning snow away from the railroad tracks at Kelly's Cut, 0.8 km (0.5 miles) west of Sleepy Eye, Minnesota, in March 1881. Image courtesy of Chicago and North Western Archives.

central Canada into the central United States, particularly along the central Plains to western Great Lakes. This ridging may correspond to the pervasive cold air outbreaks. A pressure gradient dominant from central Nebraska and central South Dakota through western South Dakota corresponded to increased surface wind speeds. Additionally, anomalously high 2-m relative humidity extended across much of the central United States, indicating moisture necessary to support heavy snowfall. Finally, upper-air patterns also favored the extreme cold and blizzard conditions.

Confidence in the description of the winter of 1880/81 in The Long Winter is increased by this meteorological data. The Hard Winter found its way into historical memory via town histories, weather and flooding records, and one woman's fictionalized stories of her youth.

\section{METADATA}

BAMS: What would you like readers to learn from this article?

\section{Barbara Mayes Boustead (University of} Nebraska-Lincoln): Literature and other creative work can provide windows into past weather and climates-including everything from documentary evidence to the impacts on individuals and communities. We can connect those works to other historical weather data sources, from observations to reanalysis data, to reconstruct what occurred, and why. By researching weather and climate related to Laura Ingalls Wilder and the Little House stories, I have been able to reach audiences who otherwise might not have been so engaged, sparking interest in weather and climate by presenting it through Laura's perspective.

BAMS: How did you become interested in researching The Long Winter?

$B M B$ : The Long Winter research began over a decade ago as I reread the book as a "comfort read" on the tail end of a winter, reminding myself that even the longest winters do eventually end. I've been reading Laura Ingalls Wilder's books since I was in elementary school, and I had always wondered if the winter was really as Wilder had described it. And then I got to thinking-I am a meteorologist, and I have the tools to look it up! The deeper I dug, the more that my questions led to more ques-

tions. I especially got excited as I found data that verified much of the weather that Wilder had described. And I knew I had found a resonant topic when I presented the work at a conference called LauraPalooza in 2010 (it's real and it's serious!) and was overwhelmed with questions and discussion following my presentation.

BAMS: What was the biggest challenge in researching this historical topic?

BMB: There were times during my research that I would have gone to great lengths to obtain true snowfall measurements from one of the observing sites near the area of interest, or to fill in the spatial gaps. Snowfall data just don't exist for the central U.S. in the early 1880s.

BAMS: What surprises most in investigating Laura Ingalls Wilder's weather?

BMB: Laura Ingalls Wilder was an excellent weather observer. Having researched the winter of 1880/81 extensively, as well as the rest of the identifiable weather and climate phenomena throughout the Little House books, I found that while many elements of the books were fictionalized, she recounted weather and climate events with great accuracy. Almost every weather or climate detail in her books really did occur and usually occurred just as she described it. She occasionally moved some timelines around, but the events themselves were spot-on. 


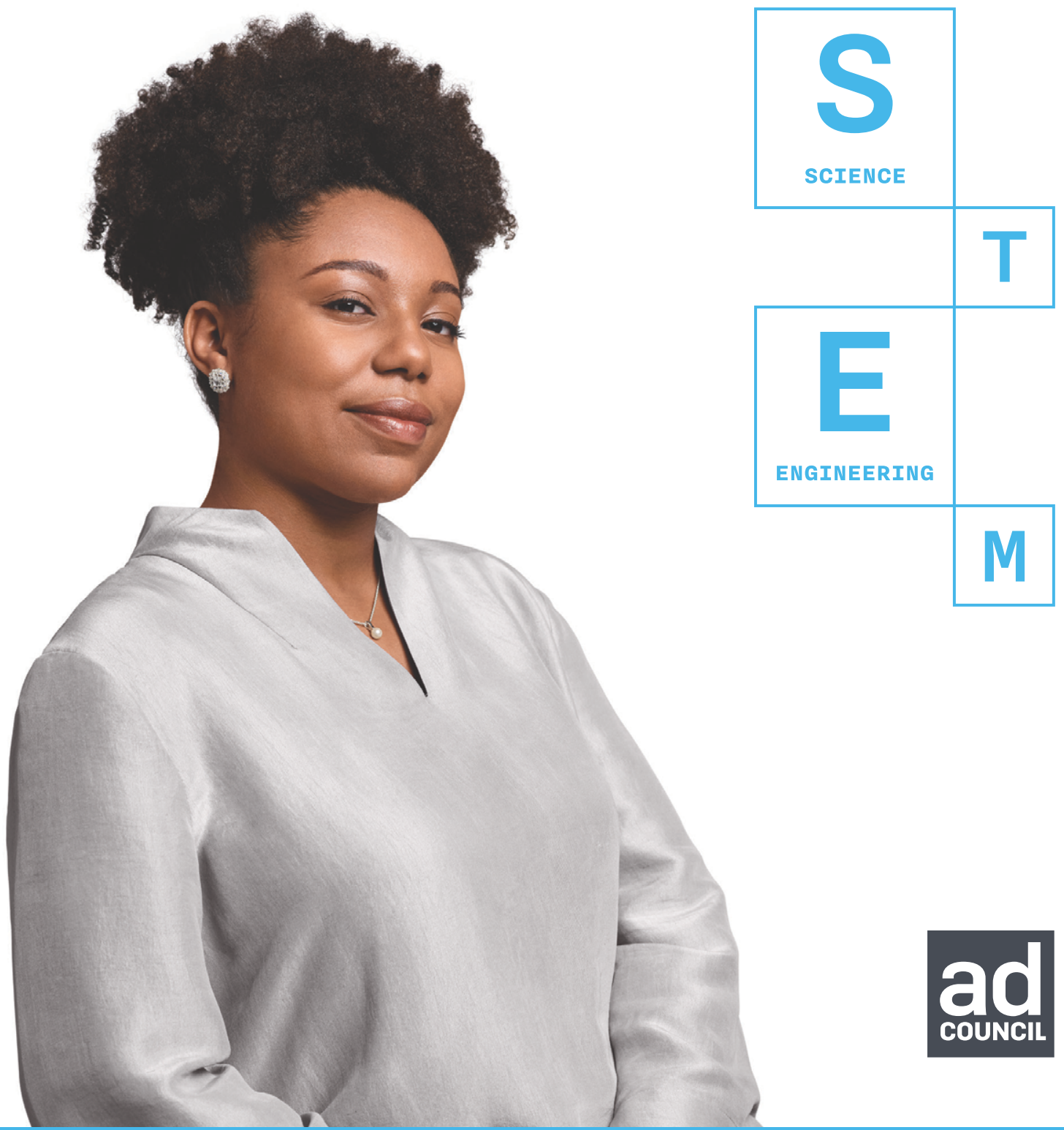

YOU ARE THE GENERATION THAT WILL BE STEPPING FOOT ON MARS.

TIERA FLETCHER

STRUCTURAL ANALYSIS ENGINEER, BOEING

GIRLS IN STEM BECOME WOMEN WHO CHANGE THE WORLD.

LEARN MORE DSHECANSTEM ON INSTAGRAM 